\section{Rock of ages}

\author{
Euan G. Nisbet
}

Science and Earth History: The Evolution/ Creation Controversy. By Arthur N. Strahler. Prometheus, Buffalo, New York: 1988. Pp.552. \$39.95. In Britain distributed from 10 Crescent View, Loughton, Essex IG10 4PZ, £29.95.

SOME of the strongest words in the Bible are reserved for those who mislead humanity by speaking falsehood and claiming that it is truth. These false shepherds - St Jude calls them clouds without rain - are those who by perverting the truth manage to lead the faithful astray. One of the most successful of the stumbling blocks, or obstacles to truth, is the pseudoscience of 'creationism', which is exploited by the legion of false prophets inhabiting the television screens of North America. The claim of 'creation scientists' is that geologists have misunderstood the Earth, and that the geological record is fully compatible with a strictly literal reading of the Bible.

Europeans, who for the most part live in a non-Christian society, often express contempt for North American culture that needs to concern itself with this claim of creation science. Why not simply ignore the charlatans and the misguided peasants who follow them? Such a view takes no account of the real strength of creationism and its record of profound influence on the political process. It also forgets the much sadder European history of the opposite phenomenon, of how the perversion of pseudo-darwinism provided the intellectual underpinning of National Socialism and the Nazi onslaught on Jews, gypsies and mental 'defectives.'

There are two defences against creationism. One is theological, the other scientific. In this long and complex book, A. N. Strahler has chosen the latter course. Creation science is an extraordinary mélange of bent evidence, misinterpretation and subtle selection of data that is based not on truth but on a value which our society places higher: credibility. It is a pseudoscience steeped in the ethics of the law courts or the opinion polls - that argument wins which is most 'credible' (that is, most loudly shouted). Strahler's book is itself not only a shout against creationism but, more important, a detailed point by point rebuttal of the farrago of untruth.

The book's length and complexity reflect the diversity of the arguments of creation science. First there is the point that in order to recognize pseudoscience we must be able to identify real science - which is nothing less than the search for truth about the natural world - and Strahler gives a long account of the contrasts between science and pseudoscience, and section is followed by detailed expositions of the contrasts between the way in which a 'mainstream' scientist views the history of the Earth and Solar System and the way in which the same evidence is seen by creationists. This naturally leads on to the age of the Earth, to Noah, Adam and Eve, and the interpretation of the fossil record.

Strahler's exposition is careful, thorough and clearly written. If at times the book appears to be disordered, that is a result of the disorderly fabric of creationism. The author pulls this fabric apart, thread by thread, and with better yarn weaves an excellent account of the fabric of mainstream natural science, especially geology. Of course, 'true' science does not stand still - we find deeper truth, or we discover flaws in our fabric - and there are sections of the text which have the dated flavour of an old textbook. But, in general, Strahler provides a fine exposition of the history and properties of the natural world. For those who, like myself, teach introductory classes in science, Science and Earth History will be a splendid source of material in the defence of still hold to the Jewish or Christian faith.

There is, however, the other defence against creationism which is less often used, though it is immensely effective. This is that creationism is, in JudaeoChristian terms, nothing less than heresy - not only because it denies truth, but because it is in opposition to the long line of Jewish and then Christian theology that began in the Jewish community in Alexandria and was developed in more detail by St Augustine in his magnificent commentary on Genesis. Karl Barth, in his comment on Romans 8.28, puts the theological position best: "we lend our support of the basic tenets of creation science. This truth, and a great help to those of us who

to all honest, secular, scientific and historical research; but we dissociate ourselves from every semi-theological interpretation of Nature and History".

By misinterpreting the English of the King James Version, creationism attacks the true meaning of both the Old and New Testaments. Augustine's discussion of time is incisive and strangely parallels Einstein's. Time, in orthodox Christianity, is not simply some consequence of the movement of a heavenly body. It is a created dimension. The 'days' of creation, like the Day discussed by the writer of the epistle to the Hebrews (Hebrews 3.13 and 4.7), are not measured by the rotation of the Earth. Augustine realized that the vision of Genesis lies outside time, in eternity. The creationists seek to trivialize God, to reduce the deity to the bounds of time: Augustine pointed out that the narrative of Genesis is a vision of truth that is concerned with something much higher than pseudoscience.

The orthodox Christian belief is that the Sun has not yet set on the seventh day of creation, despite what the creationists say, and there is a fine exposition of conservative belief in Derek Kidner's commentary on Genesis (Tyndale Press, 1973). For those whose university classes are plagued with creationism, Strahler's book, together with Kidner's essay and St Augustine's commentary on Genesis, may serve to protect the truth. Students with problems should be advised to read these, and of the television evangelists to watch only Billy Graham. Science and Earth History is a valuable rejection of the creationist heresy, for which many of us will be deeply thankful.

Euan G. Nisbet is a Professor in the Department of Geological Sciences, University of Saskatchewan, Saskatoon, Saskatchewan S7N OWO, Canada.

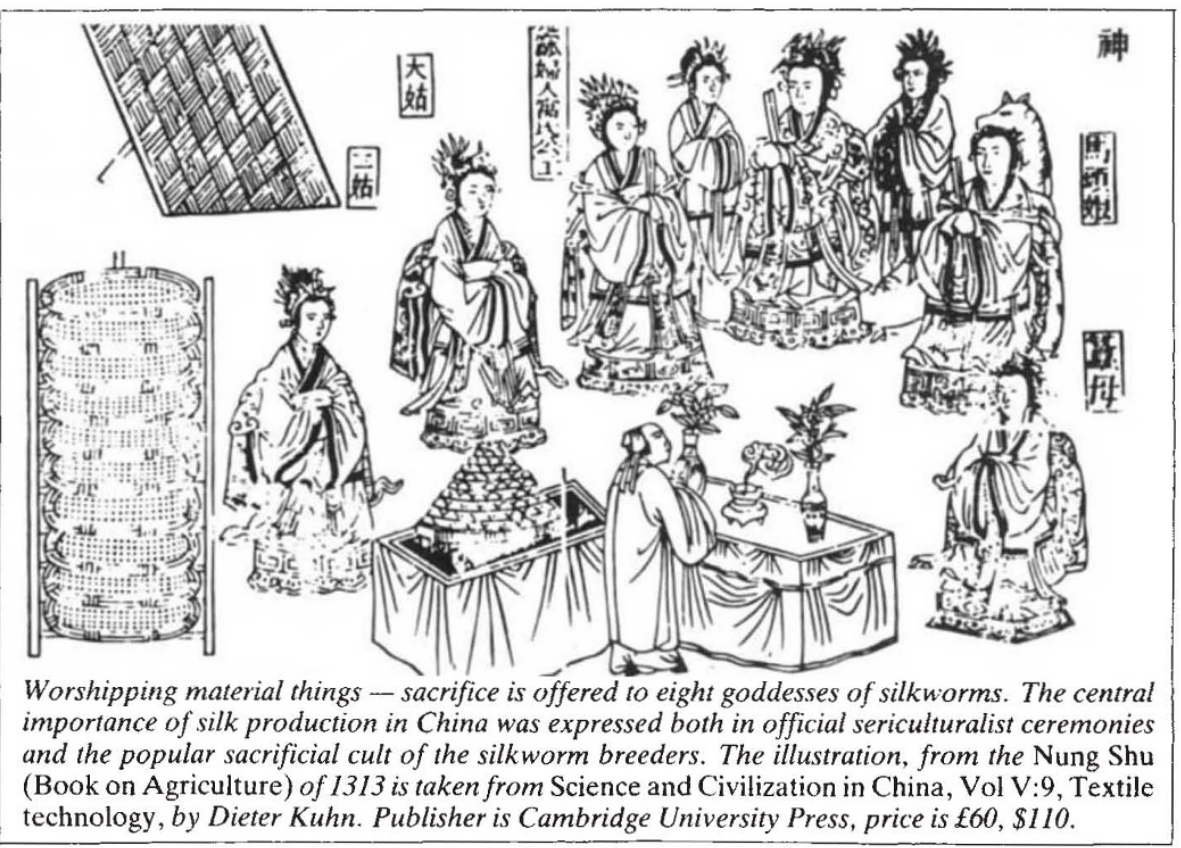

